Research Paper

\title{
Evaluation of the Effectiveness of Peritoneal Adhesion Prevention Devices in a Rat Model
}

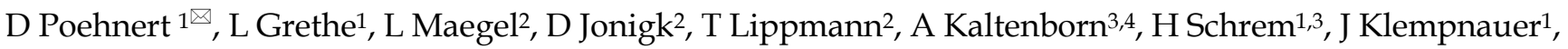 \\ M Winny ${ }^{1}$ \\ 1. Department of General, Visceral and Transplantation Surgery, Hannover Medical School, Germany; \\ 2. Institute of Pathology, Hannover Medical School, Germany; \\ 3. Core Facility Quality Management and Health Technology Assessment in Transplantation, Integrated Research and Treatment Center-Transplantation \\ (IFB-Tx), Hannover Medical School, Germany; \\ 4. Department of Trauma and Orthopaedic Surgery, Federal Armed Forces Hospital Westerstede, Westerstede, Germany. \\ $\triangle$ Corresponding author: Dr. Daniel Poehnert, PhD. Carl-Neuberg-Strasse 1, D-30625 Hannover (Germany), Tel. +49511 5326534 Fax +49511 5324010 E-Mail \\ poehnert.daniel@mh-hannover.de.
}

() Ivyspring International Publisher. Reproduction is permitted for personal, noncommercial use, provided that the article is in whole, unmodified, and properly cited. See http://ivyspring.com/terms for terms and conditions.

Received: 2016.02.01; Accepted: 2016.05.04; Published: 2016.06.30

\begin{abstract}
Background: Abdominal operations are followed by adhesions, a prevalent cause of abdominal pain, and the most frequent cause for bowel obstruction and secondary female infertility. This rat study addresses adhesion prevention capability of Adept $^{\circledR}$, Interceed ${ }^{\circledR}$, Seprafilm $^{\circledR}$, and a novel device, 4 DryField ${ }^{\circledR} \mathrm{PH}$ which is provided as powder and generates its effect as gel.

Methods: Sixty-eight male Lewis rats had cecal abrasion and creation of an equally sized abdominal wall defect, and were grouped randomly: A control group without treatment $(n=10)$; two groups treated with 4 DryField ${ }^{\circledR} \mathrm{PH}$ using premixed gel $(n=15)$ or in-situ gel technique $(n=16)$; one group each was treated with Seprafilm ${ }^{\circledR}(n=8)$, Interceed ${ }^{\circledR}(n=9)$, or Adept ${ }^{\circledR}(n=10)$. Sacrifice was on day 7 to evaluate incidence, quality, and quantity of adhesions, as expressed via adhesion reduction rate (AR). Histologic specimens were evaluated. Statistical analyses used ANOVA and unpaired t-tests.

Results: 4DryField ${ }^{\circledR} \mathrm{PH}$ significantly reduced incidence and severity of adhesions both as premixed gel (AR: $85.2 \%$ ) and as in-situ made gel (AR: 100\%), a comparison between these two application techniques showed no differences in efficacy. Seprafilm ${ }^{\circledR}$ did not reduce incidence but severity of adhesions significantly (AR: 53.5\%). With Interceed ${ }^{\circledR}$ (AR: 3.7\%) and $\operatorname{Adept}^{\circledR}$ (AR: 16.1\%) no significant adhesion-reduction was achieved. Except for inflammatory response with Interceed ${ }^{\circledR}$, histopathology showed good tissue compatibility of all other devices.

Conclusion: 4DryField ${ }^{\circledR} \mathrm{PH}$ and Seprafilm ${ }^{\circledast}$ showed significant adhesion prevention capabilities. 4DryField ${ }^{\circledR} \mathrm{PH}$ achieved the highest adhesion prevention effectiveness without restrictions concerning mode of application and compatibility and, thus, is a promising strategy to prevent abdominal adhesions.
\end{abstract}

Key words: Adhesion prevention, abdominal surgery, rat model OPAM, 4DryField ${ }^{\circledR}$ PH, Adept ${ }^{\circledR}$, Interceed ${ }^{\circledR}$, Seprafilm ${ }^{\circledR}$

\section{Introduction}

Adhesions are a serious problem following abdominal surgery ${ }^{1}$. They occur in about $90 \%$ of patients wherein $10-20 \%$ of these patients develop severe health problems ranging from pain to bowel obstruction 2. The SCAR and SCAR-2 studies from
Scotland showed that postsurgical adhesions after abdominopelvic surgery increased patients' morbidity and mortality with a readmission rate for high-risk groups such as colorectal surgery patients being one in five within four years 3,4 Although 
progress has been made in preventing adhesion-related complications since the SCAR studies, there is still need for improved adhesion prevention.

Postoperative adhesions mostly develop as a result of peritoneal injury, cell death and blood remnants, resulting in fibrin deposition ${ }^{5}$. Surgical methods to reduce postoperative adhesion formation involve minimal tissue handling and reduced peritoneal trauma 6, 7. These strategies can help to lower but not completely prevent the incidence of adhesions. Furthermore, they are limited due to the fact that they are not always accessible and/or applicable. Therefore, the development of adhesion prevention agents and devices is essential 6,8 .

Pharmacological agents are still in an experimental stage and are not yet available in surgical practice. Additionally, they bear the disadvantage of involving the whole metabolism of individuals 9 .

A preferable adhesion prevention device should be easy to use and exhibit its action only locally with no harm to the patient. Since peritoneal recovery is known to occur within three to five days, devices should be degraded quickly after this timeframe to avoid adverse events which could cause secondary adhesions ${ }^{10,11}$. Medical devices acting as local barriers have been introduced into clinical practice, but their efficiency is discussed controversially 12 . Non-absorbable synthetic materials such as silicone and polytetrafluoroethylene (PTFE) have been shown to possess a certain degree of effectiveness, however, they need to be removed after some time ${ }^{12}$. Therefore, bio-absorbable materials based on degradable components are preferable ${ }^{12}$. Although several such degradable devices have been introduced into the market, no single product has been found wholly satisfactory so far ${ }^{6,12-14}$.

Up to now, devices based on hyaluronic acid have shown some effectiveness. However, studies also indicate, that their use corresponds to an increased leakage rate of intestinal anastomoses, limiting their spectrum of use in abdominal surgery ${ }^{15}$, 16. In this study, Seprafilm ${ }^{\circledR}$ (Genzyme $\mathrm{GmbH}$, Germany) consisting of modified hyaluronic acid/carboxymethylcellulose applicable as a membrane was evaluated. Furthermore, Interceed ${ }^{\circledR}$ (Ethicon, USA) which is an absorbable knitted fabric prepared by the controlled oxidation of regenerated cellulose was appraised. Both, Seprafilm ${ }^{\circledR}$ and Interceed ${ }^{\circledR}$ are administered directly on the areas at risk for adhesion formation and are mainly used in open abdominal or gynecological surgery. Adept $t^{\circledR}$ (Baxter Healthcare Corporation, USA), on the other hand, a $4 \%$ icodextrin solution, is a liquid adhesion barrier prevention applicable for both, open and laparoscopic surgery. Delivered into the peritoneal cavity it is believed to mediate its effect by providing a temporary separation of peritoneal surfaces by hydroflotation as a result of maintaining a fluid reservoir. 4DryField ${ }^{\circledR} \mathrm{PH}$ (PlantTec Medical, Germany) is a new plant-based polysaccharide for adhesion prevention and haemostasis. The powder is applied to the areas at risk and then transformed into a gel in-situ with a saline solution. Alternatively, in this study 4 DryField ${ }^{\circledR} \mathrm{PH}$ gel was premixed before application and can be applied in open as well as in minimally invasive surgery.

Comprehensive clinical testing of adhesion prevention devices implies the necessity of a second look operation with the involved ethical problems 6,12 . Due to high variability of anatomy and diseases, standardization is extremely difficult, especially if an actual comparison of different devices is the objective $^{12}$. Accordingly, animal experiments represent the alternative tool for comparative studies. Recently, we have introduced an optimized adhesion model (OPAM) proven to induce severe adhesions with high reproducibility ${ }^{17}$. Using OPAM, 4 DryField ${ }^{\circledR} \mathrm{PH}$ applied as premixed gel could be shown as highly effective in preventing adhesion formation ${ }^{18}$. The study presented herein uses the same challenging model to rank efficacy of the market leading adhesion barrier devices Seprafilm ${ }^{\circledR}$, Interceed ${ }^{\circledR}$ and Adept ${ }^{\circledR}$ in comparison to 4 DryField ${ }^{\circledR}$ $\mathrm{PH}$ applied with two different variants of application.

\section{Methods}

\section{Animals}

Our study was approved by The Lower Saxony State Office for Consumer Protection and Food Safety (LAVES, Hannover, Germany; approval code 13/1095). All experiments were performed at the Zentrales Tierlabor of Hanover Medical School (MHH, Hanover, Germany). In order to provide and assure adequate life quality of the laboratory animals all protocols were conducted in accordance with national and European animal protection laws.

A total of 68 male Lewis rats, weighing between $270 \mathrm{~g}$ and $423 \mathrm{~g}$ (mean $328 \mathrm{~g} \pm 34 \mathrm{~g}$ ) were used. Animals were housed under standard conditions and were fed ad libitum with a commercial diet and had continuous access to fresh water. Animals' welfare was assessed by daily monitoring of bodyweight and behavioural changes with the use of a observation chart (body condition scoring, GV-SOLAS, Charite Universitätsmedizin Berlin, Berlin, Germany).

\section{Surgical procedure}

General anaesthesia for surgical intervention 
was achieved using a dose of $80 \mathrm{mg} / \mathrm{kg}$ body weight ketamine and $5 \mathrm{mg} / \mathrm{kg}$ xylazine. The required level of narcosis for surgery was reached, when flexor reflexes were suppressed.

In all animals, after shaving and sanitising of the abdomen a three $\mathrm{cm}$ long median laparotomy was performed. To induce peritoneal adhesion, the previously reported OPAM technique was used to induce severe and reproducible adhesions for testing adhesion prevention agents in a severe case scenario. In the OPAM technique, peritoneal adhesions were induced by peritoneal abrasion of the caecum and dissecting the inner skeletal muscle layer of the abdominal wall, followed by a meso-stich approximation of both injured areas ${ }^{17}$.

Prior to surgery, the animals were randomly divided into six different groups: the control group without any adhesion prevention treatment (CT, $\mathrm{n}=10$ ); two groups were treated with 4 DryField $^{\circledR} \mathrm{PH}$ in different application modes (premixed gel, $\mathrm{n}=15$; in-situ gel, $\mathrm{n}=16$ ); one group each was treated with Seprafilm ${ }^{\circledR}(S F, n=8)$, Interceed ${ }^{\circledR}(I C, n=9)$, or Adept ${ }^{\circledR}$ $(\mathrm{AD}, \mathrm{n}=10)$, respectively.

\section{Application of anti-adhesive agents}

All products were only applied after sufficient haemostasis was achieved by time. 4 DryField $^{\circledR} \mathrm{PH}$ was applied in two different application modes, both using $300 \mathrm{mg}$ of 4 DryField $^{\circledR}$ PH per animal. One group received treatment with 4 DryField ${ }^{\circledR} \mathrm{PH}$ gel premixed extra-corporally with $0.9 \%$ saline solution resulting in a concentration of $0.25 \mathrm{mg} 4$ DryField $^{\circledR} \mathrm{PH}$ per $\mathrm{ml}$, i.e. $1.2 \mathrm{ml}$ gel/animal (Fig. $1 \mathrm{C}$ ). The other group received 4 DryField ${ }^{\circledR} \mathrm{PH}$ with in-situ gel technique, i.e. powder was first placed on the sites of injury and subsequently a gel was generated in-situ by dripping with saline solution (0.9\%) (Fig. $1 \mathrm{E}$ and F). One group each was treated with the adhesion prevention membranes Seprafilm ${ }^{\circledR}$ and Interceed $^{\circledR}$. Prior to positioning, Interceed ${ }^{\circledR}$ and Seprafilm ${ }^{\circledR}$ membranes were trimmed according to the size of the OPAM injury and then placed to separate the abdominal wall and the abraded caecum (Fig. $2 \mathrm{~A}$ and C). Adept ${ }^{\circledR}$ was delivered as a liquid directly into the peritoneal cavity in an amount of $12.5 \mathrm{ml} / \mathrm{kg}$ bodyweight before closure of the abdominal cavity as demonstrated in Figure $2 \mathrm{E}$.

After surgery animals were monitored until complete awakening and kept warm with an infrared lamp. To minimise expectable postoperative pain animals received Novalminsulfone in the immediate postoperative period (non-recurring subcutaneously after surgery with $200 \mathrm{mg} / \mathrm{kg}$ body weight; subsequently by mixing 40 droplets to $500 \mathrm{~mL}$ drinking water). If complications had occurred (e.g. infection or inflammation), the affected animals would have been sacrificed immediately.

\section{Parameters of Outcomes}

At day seven after surgery, animals were sacrificed by carbon dioxide narcosis followed by cervical dislocation. Afterwards, the peritoneal cavity was opened by an incision at a left-sided position remote to the original laparotomy scar in order to prevent disturbing any potential adhesions. The extent of adhesion formation was evaluated by two independent observers according to the scoring schemes of Lauder et al. ${ }^{13}$ and Hoffmann et al. ${ }^{14}$.

The Lauder scoring scheme takes into account number, strength, and distribution of adhesions, resulting in the adhesion scores: 0: no adhesions, 1: thin filmy adhesions, 2: more than one thin adhesion, 3: thick adhesions with focal point, 4: thick adhesions with planar attachment, 5: very thick vascularised adhesions or more than one planar adhesion.

With the Hoffmann scoring scheme and grading scale gross adhesions were assessed and expressed as a percentage of the total de-peritonealised surface area. This was further translated into grades 0 to 4 (0: no adhesions, 1: caecum to bowel adhesion, 2: caecum to sidewall adhesion over less than $25 \%$ of the abraded surface area, 3: caecum to sidewall adhesion between $25 \%$ and $50 \%$ of the abraded surface area, 4 : caecum to sidewall adhesion over $50 \%$ of the abraded surface area). Each animal additionally was evaluated for strength of adhesion formation and graded 0 to 3 (0: no adhesion, 1: gentle traction required to break adhesion, 2: traction required to break adhesion, 3: sharp dissection required to break adhesions. The extent of adhesion formation was also graded 0 to 3 (0: no adhesion, 1: filmy adhesion, 2: vascularized adhesion, 3: opaque or cohesive adhesion). These three sub-scores were summed for a total adhesion score. Photographs of the affected areas were taken from each animal for documentation purposes (20.0 megapixel digital camera, Cyber-shot DSC-RX100, Sony, Germany).

For a better comparison of tested devices an 'adhesion reduction rate' (AR) was calculated. Hoffmann total and Lauder scores were set against the corresponding score of controls expressed in percentages. Values were averaged and then subtracted from 100 to allow expression as reduction rate. This means if there was no adhesion formation, the adhesion reduction rate was $100 \%$.

Specimens for histological examinations of OPAM areas, in particular of adhesions, were collected. Samples were excised en bloc, rinsed, and immersed in $4 \%$ buffered formalin. After paraffin embedding, serial sections were stained with 
haematoxylin and eosin or with a PAS staining kit and evaluated by light microscopy in a blinded fashion.

\section{Statistical analyses}

Adhesion scores are presented in mean values with standard deviations (SD). Scores and weight data were compared using unpaired t-test and reported $\mathrm{p}$ values and were considered significant with $\mathrm{p}<0.05$. Additionally, one-way ANOVA testing was performed for multiple comparisons of adhesion reduction rates of all treatment groups. Statistical analyses were performed with GraphPad PRISM (Version 6 for Mac OS, GraphPad Software, Inc., La Jolly, USA). Significance levels were defined as: $<0.0001=$ highly significant $\left(^{* * *}\right),<0.005=$ moderately significant $\left(^{* *}\right)$ and $<0.05=$ significant $\left(^{*}\right)$.

\section{Results}

None of the animals had to be sacrificed during the postoperative course; a total of 68 animals completed the study. Rats in all groups showed equitable viability and course of body weight.

\section{Adhesion Scores}

In none of 68 animals congenital adhesions were noted at the initial laparotomy. Individual adhesion scores for each group at pathological evaluation are shown in Table 1.

In the control group (Fig. $1 \mathrm{~A}$ and B) 9 of 10 animals developed severe adhesions and agglutination of the caecum to the abdominal wall (Fig. 1 B). Subjected to adhesion scoring systems, a mean Lauder score ${ }^{13}$ of $4.5 / 5$ and total Hoffmann score ${ }^{14}$ of $9 / 10$ was assigned, respectively. Three of 15 animals treated with 4 DryField ${ }^{\circledR} \mathrm{PH}$ premixed gel (Fig. $1 \mathrm{C}$ and D) had detectable adhesions (Lauder score $0.5 / 5$, total Hoffmann score 1.6/10). In contrast, none of 16 animals in the group with 4 DryField $^{\circledR} \mathrm{PH}$ applied as in-situ gel (Fig. 1 E-G) developed any adhesions of the caecum to the abdominal wall (Fig. 1 $\mathrm{G)}$. This resulted in a score of 0 for both soring systems. There was no statistical difference between 4 DryField ${ }^{\circledR} \mathrm{PH}$ treated groups when comparing both adhesion scores.

Of the eight rats treated with Seprafilm ${ }^{\circledR}$ (Fig. 2 A and $\mathrm{B})$, seven animals revealed minor to severe adhesions (Fig. 2 B), while one was free of adhesion formation at autopsy. This corresponds with the incidence in controls. However, the severity of adhesions was reduced, as indicated by lower mean Lauder and Hoffmann scores. Following treatment with Interceed ${ }^{\circledR}$ (Fig. 2 C and D) eight of nine animals had severe adhesions; Interceed ${ }^{\circledR}$ remnants were visible in the agglutination areas (Fig. 2 D), and one rat had no adhesions. All of ten Adept ${ }^{\circledR}$ treated animals (Fig. $2 \mathrm{E}$ and F) showed at least some adhesion formation (Fig. $2 \mathrm{~F}$ ), with six of ten animals having severe adhesions.
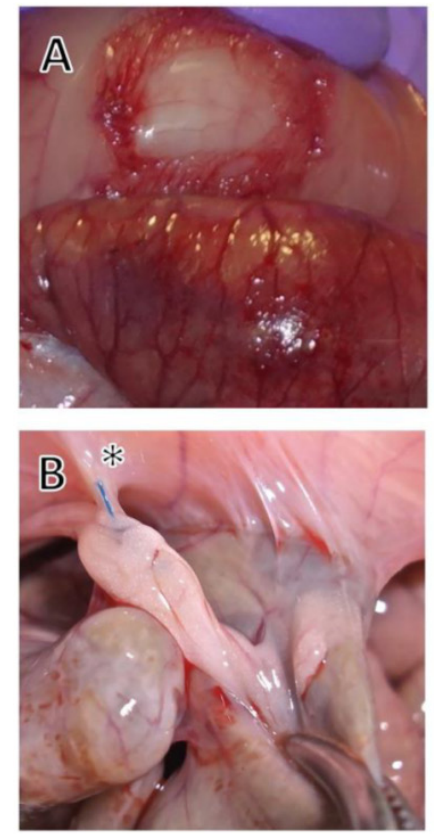
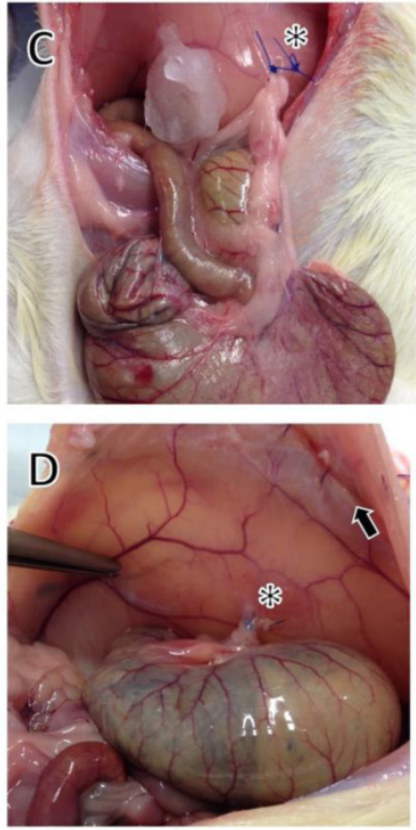
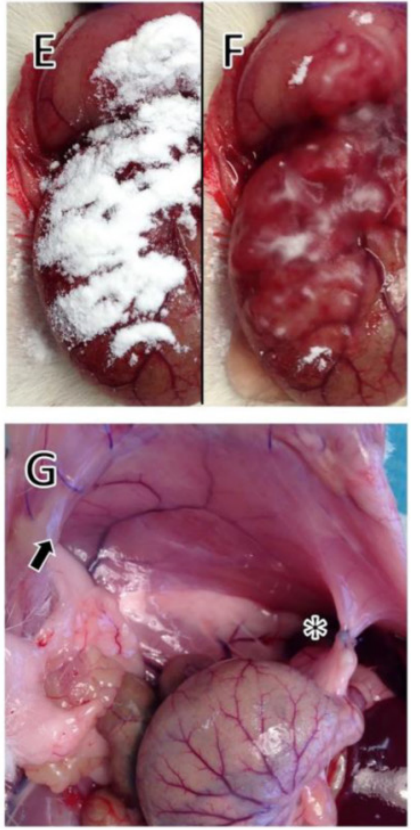

Figure 1: Photographs at surgery and pathological evaluation in a control animal (A and B) and animals with 4DryField ${ }^{\circledR} \mathrm{PH}$ premixed gel $(\mathrm{C}$ and $\mathrm{D})$ and in-situ gel treatment ( $E, F$ and $G)$. Arrows indicate laparotomy scars, asterisks demonstrate the approximation of abdominal wall and caecum by meso-stich. (A) Site after optimized adhesion model (OPAM) surgery, i.e. creation of abdominal wall defect and abrasion of caecum. (B) Control animal at day 7 after OPAM with caecum agglutinated to abdominal wall. (C) Site after OPAM and treatment with 4DryField ${ }^{\circledR} \mathrm{PH}$ as premixed gel. Note the meso-suture for approximation of caecum and abdominal wall. (D) Day 7 after premixed gel treatment revealing no adhesions, tip of forceps points to the area of the former abdominal wall defect. Peritoneum reveals a shiny surface in the area of the former OPAM injuries. (E) Site after application of 4DryField ${ }^{\circledR} \mathrm{PH}$, (F) after dripping with saline solution a 4DryField ${ }^{\circledR}$ PH gel was formed (in-situ mixed gel). (G) Site of surgery following 4DryField ${ }^{\circledR} \mathrm{PH}$ in-situ gel treatment revealing no adhesion formation. 
Table 1: Lauder score and Hoffmann scores (total and sub scores).

\begin{tabular}{|c|c|c|c|c|c|c|}
\hline & Controls & 4 DryField ${ }^{\circledR}$ premixed gel & 4DryField ${ }^{\circledR}$ in-situ gel & Seprafilm ${ }^{\circledR}$ & Interceed ${ }^{\circledR}$ & Adept $^{\circledR}$ \\
\hline Lauder Score & $4.5 \pm 1.6$ & $0.5 \pm 1.2$ & $0.0 \pm 0.0$ & $1.9 \pm 1.4$ & $4.3 \pm 1.7$ & $3.4 \pm 1.4$ \\
\hline \multicolumn{7}{|l|}{ Hoffmann Score } \\
\hline area & $3.6 \pm 1.3$ & $0.7 \pm 1.4$ & $0.0 \pm 0.0$ & $1.5 \pm 1.1$ & $3.4 \pm 1.3$ & $3.2 \pm 1.5$ \\
\hline strength & $2.7 \pm 0.9$ & $0.5 \pm 1.1$ & $0.0 \pm 0.0$ & $1.8 \pm 1.0$ & $2.6 \pm 1.0$ & $2.4 \pm 1.0$ \\
\hline extend & $2.7 \pm 0.9$ & $0.5 \pm 1.1$ & $0.0 \pm 0.0$ & $1.4 \pm 0.9$ & $2.7 \pm 1.0$ & $2.7 \pm 0.9$ \\
\hline total & $9.0 \pm 3.2$ & $1.6 \pm 3.6$ & $0.0 \pm 0.0$ & $4.6 \pm 2.7$ & $8.7 \pm 3.3$ & $8.3 \pm 3.2$ \\
\hline Adhesion reduction rate (AR) & 0 & $85.2 \%$ & $100 \%$ & $53.5 \%$ & $3.7 \%$ & $16.1 \%$ \\
\hline p (AR) vs. control & & $<0.0001$ & $<0.0001$ & 0.0035 & 0.8245 & 0.3071 \\
\hline
\end{tabular}
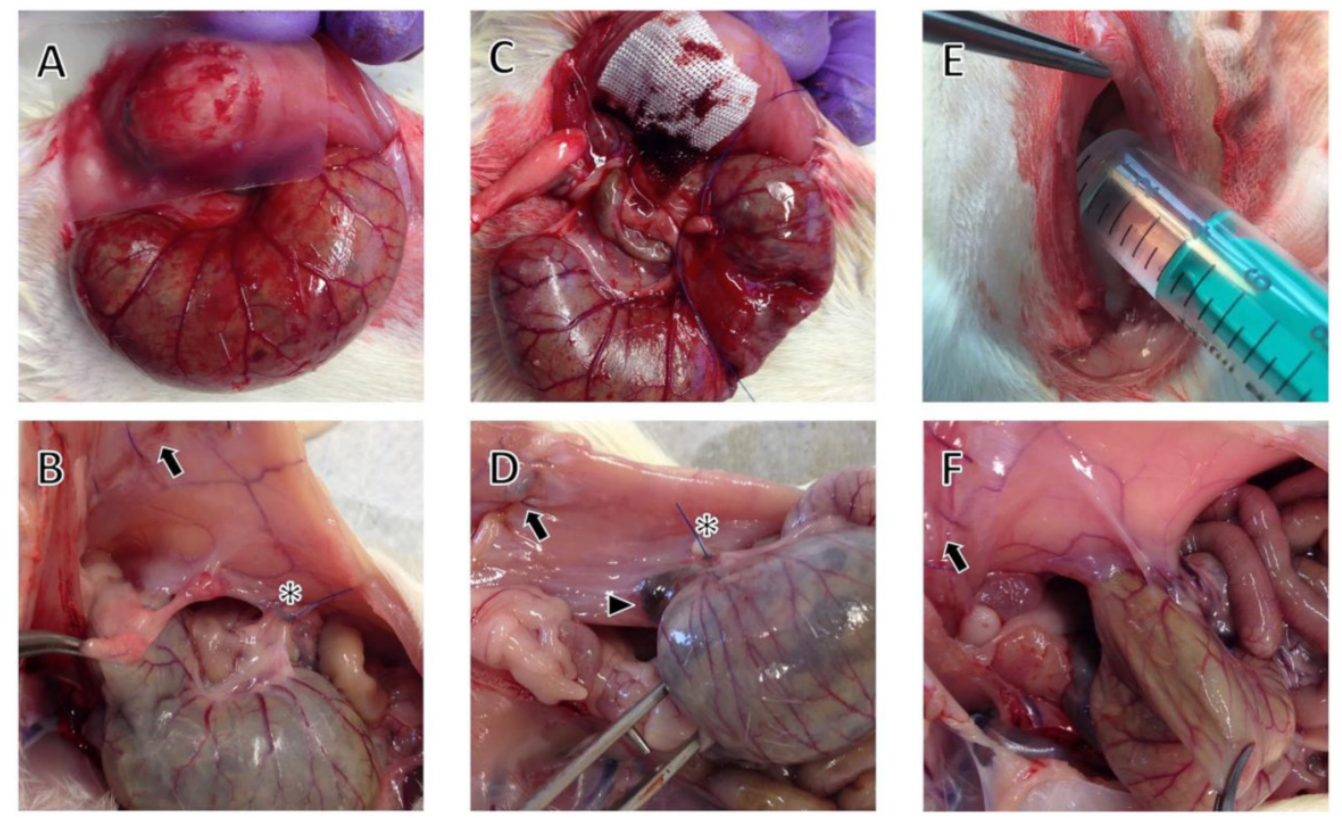

Figure 2: Photographs at surgery (A, B, C) and pathological evaluation at day seven (D, E, F) in rats with Seprafilm ${ }^{\circledR}$, Interceed ${ }^{\circledR}$, and Adept ${ }^{\circledR}$ treatment. Arrows indicate laparotomy scars, asterisks the meso-stich approximation of abdominal wall and caecum, arrowhead indicates Interceed ${ }^{\circledR}$ remnant. (A) Patch of Seprafilm ${ }^{\circledR}$ is applied to separate abdominal wall defect and abraded caecum. (B) Agglutinations after Seprafilm ${ }^{\circledR}$ application. (C) Patch of Interceed ${ }^{\circledR}$ is applied to abdominal wall defect. (D) Remnant of Interceed ${ }^{\circledR}$ agglutinated to the abdominal wall on one side and the caecum on the other side. (E) Application of Adept ${ }^{\circledR}$ intraperitoneally (12.5 $\mathrm{ml} / \mathrm{kg}$ bodyweight). (F) Adherence of the caecum after treatment with Adept ${ }^{\circledR}$.

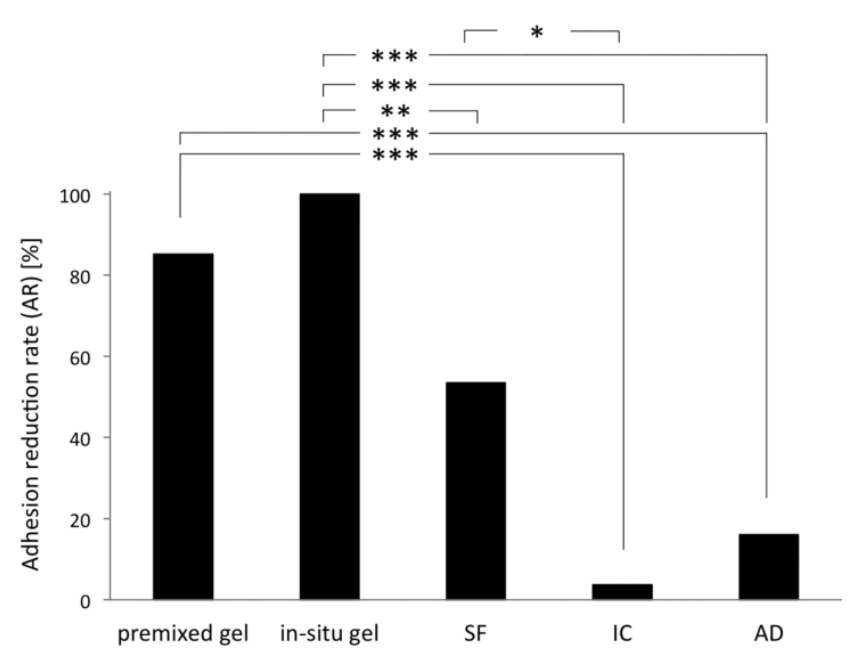

Figure 3: Adhesion reduction rates of 4 DryField ${ }^{\circledR} \mathrm{PH}$ premixed gel, 4DryField ${ }^{\circledR} \mathrm{PH}$ in-situ-mixed gel, Seprafilm ${ }^{\circledR}(\mathrm{SF})$, Interceed ${ }^{\circledR}(\mathrm{IC})$, and Adept $^{\circledR}$ $(A D)$.
Compared to controls, 4DryField ${ }^{\circledR} \mathrm{PH}$ treated rats showed a significant $(\mathrm{p}<0.0001)$ adhesion reduction rate of $85.2 \%$ for premixed gel and of $100 \%$ for in-situ gel treatment $(p<0.0001)$ (no therapy failure in this group). A significant ( $\mathrm{p}=0.0035)$ adhesion reduction rate was also noted in animals with Seprafilm ${ }^{\circledR}$ treatment as compared to controls, whereas treatment with Interceed $^{\circledR}$ and Adept $^{\circledR}$ revealed no statistically significant benefit with respect to adhesion prevention (Table 1 ).

Figure 3 shows the adhesion reduction rate (AR) of all groups in a multi comparison analysis of the adhesion reduction rates. Herein, 4 DryField $^{\circledR} \mathrm{PH}$ premixed gel showed a significantly better adhesion prevention compared to Adept $^{\circledR}$ and Interceed ${ }^{\circledR}$. 4 DryField ${ }^{\circledR} \mathrm{PH}$ in-situ-mixed gel reduced adhesions significantly better than Adept $^{\circledR}$, Interceed ${ }^{\circledR}$ and Seprafilm ${ }^{\circledR}$. Seprafilm ${ }^{\circledR}$ showed significantly better adhesion prevention than Interceed ${ }^{\circledR}$. 
Taken together, the adhesion score data provide evidence for a superior adhesion prevention by 4DryField $\mathrm{PH}^{\circledR}$ as a premixed and in-situ mixed gel without significant differences between both application modes.

\section{Histologic Findings}

Histopathological observations at day seven after OPAM treatment confirmed the macroscopic rating of adhesion formation for all groups. Figure $4 \mathrm{~A}$ gives a representative example of agglutinations in a control group animal, showing the smooth muscles of the caecum fused to the skeletal muscles of the abdominal wall via dense granulating tissue. The histological findings support the macroscopic observation that caecum and abdominal wall could not readily be separated by mechanical force.
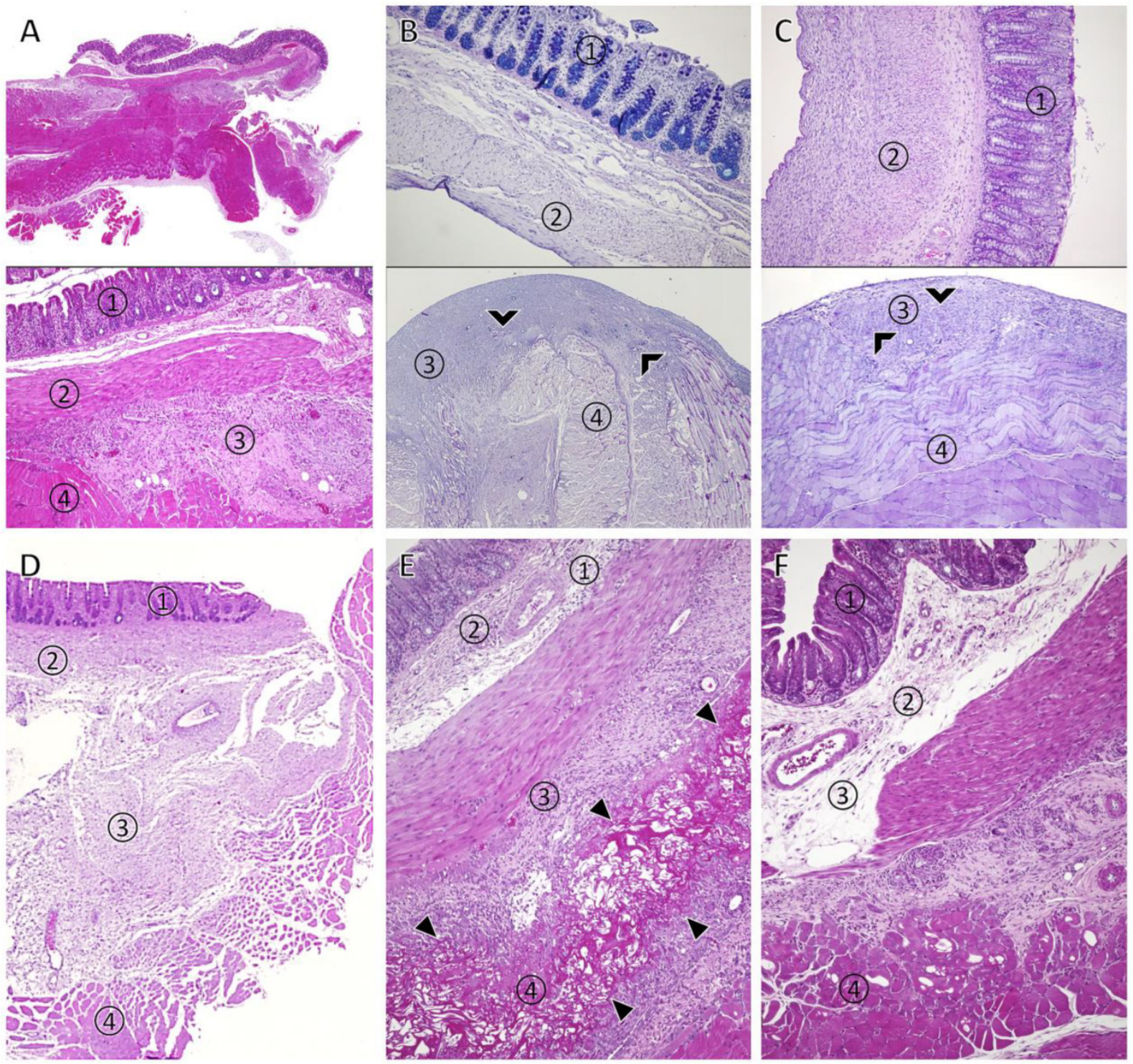

Figure 4: Representative photomicrographs of tissues from animals of control and treatment groups taken one week after operation. 1: cecal mucosa, 2: smooth muscle layer of the caecum, 3: granulating tissue, 4: abdominal wall musculature (A) HE-staining in a control animal with agglutination of abdominal wall and caecum (top: overview, bottom: close-up of the agglutination site of abdominal wall and caecum connected by granulating tissue). (B) animal of $4 \mathrm{DryField}{ }^{\circledR} \mathrm{PH}$ premixed gel group, PAS-staining: Caecum (top) and abdominal wall (bottom) show no agglutination. A slight thickening of the sub-peritoneal tissue of the abdominal wall above the former abdominal wall defect and some remnants of 4DryField ${ }^{\circledR} \mathrm{PH}$ are visible (chevron arrowheads). (C) animal of 4DryField ${ }^{\circledR} \mathrm{PH}$ in-situ-mixed gel group, PAS-staining: Caecum (top) and abdominal wall (bottom) show no agglutination but a slight sickening of the sub-peritoneal tissue of the abdominal wall with some remnants of 4DryField ${ }^{\circledR}$ PH. (D) Animal treated with Seprafilm ${ }^{\circledR}$ revealing agglutination of abdominal wall and caecum. (E) Interceed ${ }^{\circledR}$-treated animal with deposits of the product surrounded by granulating tissue (delta arrowheads), via which abdominal wall and caecum are agglutinated. (F) Adept ${ }^{\circledR}$-treated animal with agglutination of caecum and abdominal wall. Original magnification: A, top: 20x; A, bottom and B-F: 100x. 
In contrast, no agglutinations occurred in the majority of animals treated with 4 DryField $^{\circledR} \mathrm{PH}$ irrespective of treatment with premixed or in-situ mixed gel. The wounds of the caecum and the area of the abdominal wall defect had healed, both were covered with a single mesothelial cell layer. Figure 4 B and $C$ (top panels) show representative findings from the areas of healed caecum (B: premixed gel, C: in-situ mixed gel) without signs of the former injury or 4 DryField $^{\circledR}$ PH remnants. Figure 4 B and C (bottom panels) are representative histologic views from the area of the former abdominal wall defect revealing a slightly thickened sub-mesothelial layer with some remaining polysaccharide particles in varying stages of degradation in both, the premixed (Fig. 4 B) and the in-situ mixed gel (Fig. 4 C) groups. Figure $4 \mathrm{D}$ shows a histological specimen taken from an agglutinated area in a Seprafilm ${ }^{\circledR}$-treated animal. Adhesions consisted of granulating tissue like in the control group. No remnants of Seprafilm ${ }^{\circledR}$ could be detected with HE or PAS-staining one week after implantation. After treatment with Interceed ${ }^{\circledR}$, substantial remnants of the device were present in all animals. The device was infiltrated and surrounded by mononuclear inflammatory cells, haematoma and granulating tissue were visible in this area (Fig. 4 E, arrowheads). Agglutinations in Adept ${ }^{\circledR}$-treated animals were comparable to controls with a tight connection of caecum and abdominal wall by granulating tissue (Fig. 4 F). Remnants of icodextrin-polysaccharide were not delimitable.

In sum, histologic observations confirmed our macroscopic findings. OPAM controls regularly revealed severe agglutinations. With 4 DryField $^{\circledR} \mathrm{PH}$ treatment mostly a single-layer peritoneal cell coverage had developed covering the areas of injury. The sub-mesothelial connective tissue was thickened and contained sparse remnants of polysaccharide. In Seprafilm ${ }^{\circledR}$ or Adep $^{\circledR}{ }^{\circledR}$ treated animals, agglutinations were comparable to those of control animals. Interceed $^{\circledR}$ remnants were found in substantial amounts in agglutination sites associated with local inflammatory response.

\section{Discussion}

Adhesion formation is a clinical problem associated with increased patients' impairment and morbidity as well as considerable health care costs ${ }^{1,2}$. One of the most important triggers for this complication is abdomino-pelvic surgery 3, 4. Many attempts have been made to solve this burden. The pharmacological approach is still in the experimental stage ${ }^{9}$. A number of medical devices acting as temporary mechanical barriers have been introduced into clinical practise, but none of those has been completely satisfying 6, 12-14. Decision-making for adhesion prevention strategies is complex and should be based on experimental and, if possible, clinical surveys.

The present study investigates the effectiveness of four adhesion prevention devices. Although clinical proof of effectiveness is crucial, it is generally difficult to achieve in the clinical setting and animal studies provide a basis for comparative evaluation of anti-adhesive agents. Such studies allow postoperative observation of individuals and patho-anatomical analysis of macroscopic and microscopic findings. The recently introduced optimized adhesion model (OPAM) ${ }^{17}$, which induces formation of severe adhesions with consistent reproducibility in rats, is appropriate for testing and comparing adhesion prevention devices in a worst case scenario.

Recently, we used OPAM to investigate the adhesion prevention capability of 4 DryField ${ }^{\circledR} \mathrm{PH}$. We found a $90 \%$ adhesion reduction rate 18 , which can be considered as superior, when compared with results of recent experimental publications employing other devices, such as Seprafilm ${ }^{\circledR} 19-21$, Interceed $^{\circledR} 21-23$ and Adept $^{\circledR}$ 20, 23-25.

In the present study, the again favourable outcome with 4 DryField ${ }^{\circledR} \mathrm{PH}$ gel, used as premixed or as in-situ version, supports the results of a previous investigation ${ }^{18}$. Since both application techniques are appropriate, the mode of administration can be adjusted to the surgical needs without loss of effectiveness ${ }^{18}$. Translated into clinical practice, the in-situ gel technique might be suitable for the treatment of large oozing peritoneal defects. Accordingly, large areas depleted from peritoneum as found in redo surgery for symptomatic adhesions might be treated with the premixed gel version. The histologic results showing full reconstitution of the peritoneal coverage are important since peritoneal impairment is a key factor for the induction of adhesions ${ }^{11,26 .}$.

Efficiency of different adhesion prevention devices can be compared best when testing is performed in the same experimental setup, as in the present series. The observation that Seprafilm ${ }^{\circledR}$ shows some efficiency corresponds well with data recently published, indicating that hyaluronate carboxymethylcellulose reduces the incidence of reoperations for adhesive small bowel obstruction ${ }^{15}$. However, there is information that the use of Seprafilm ${ }^{\circledR}$ might be associated with an increased risk of intestinal anastomotic insufficiency and infection ${ }^{16}$, 27,28 . This possibly limits its clinical use in surgeries with bowel anastomoses.

With the worst-case scenario of the present 
study, for Interceed ${ }^{\circledR}$ and Adept $^{\circledR}$ a significant adhesion reduction could not be shown. The inflammatory response after Interceed $^{\circledR}$ application might be due to the longer degradation time of oxidized cellulose while absorption of 4 DryField ${ }^{\circledR} \mathrm{PH}$, Seprafilm ${ }^{\circledR}$ and Adept ${ }^{\circledR}$ is much faster, as supported by our results. However, prolonged presence of substantial quantities of Interceed ${ }^{\circledR}$ might induce an inflammatory foreign body reaction, which is known to be a trigger for adhesion formation ${ }^{29}$. Unlike all other products, Adept $^{\circledR}$ was not detectable in photomicrography (data not shown).

Haematoma and fibrin bands are also known to be a potential basis for adhesion formation 10, 11 . Therefore, all devices in the present study were only applied after achievement of sufficient haemostasis, as delineated by manufacturers in the instructions for use. Experimentally and clinically, secondary oozing is not always completely avoidable in larger wounds. Thus, the dual effect of 4 DryField $^{\circledR} \mathrm{PH}$ providing haemostasis and adhesion prevention might have contributed to its superior results. Furthermore, this might also be the reason for the slight difference between premixed and in-situ gel. The primarily administered 4DryField ${ }^{\circledR} \mathrm{PH}$ powder optimized haemostasis of the wound bed, the gel formed the adhesion barrier.

Whilst human studies are missing, experimental data indicate that a marked reduction of peritoneal adhesion formation can be achieved with a good surgical technique, adequate pneumoperitoneum and prevention of desiccation 7 . However, since these methods cannot completely prevent adhesions and are not always applicable, the use of adhesion barriers should be taken in consideration 6,11. Manufacturers

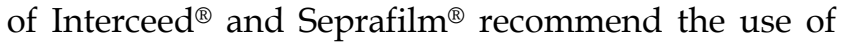
their devices for open surgery, whereas 4 DryField $^{\circledR}$ $\mathrm{PH}$ and Adept ${ }^{\circledR}$ can be applied in both, laparoscopic and open surgery.

The experimental results of the present study clearly underline the efficiency of 4 DryField $^{\circledR} \mathrm{PH}$, which is already supported by initial clinical results ${ }^{30}$. In a study on gynaecological patients with surgery for severe endometriosis, uterus disease or extensive symptomatic adhesions, 4 DryField ${ }^{\circledR} \mathrm{PH}$ was shown to be efficient, also confirmed with second look laparoscopies ${ }^{30}$. The present experimental study on caecal adhesions provides a basis for trials in visceral surgery, known to have a high readmission rate due to adhesion-related complications, especially after colorectal surgery.

\section{Conclusion}

In an experimental model known to induce severe adhesions 4 DryField $^{\circledR} \mathrm{PH}$ gel significantly reduced incidence and severity of adhesion formation. Seprafilm ${ }^{\circledR}$ did not diminish incidence but significantly reduced adhesion severity, whereas Adept $^{\circledR}$ and Interceed ${ }^{\circledR}$ demonstrated no significant adhesion prevention capabilities. With Interceed ${ }^{\circledR}$ a local inflammatory reaction was seen, whereas all other devices revealed good tissue compatibility. Due to the favourable results, 4 DryField $^{\circledR} \mathrm{PH}$ gel can be recommended as a promising strategy against the burden of adhesion formation following abdomino-pelvic surgery.

\section{Competing Interests}

The authors have no conflicts of interest to disclose.

\section{References}

1. Ellis H, Moran BJ, Thompson JN, Parker MC, Wilson MS, Menzies D, McGuire A, Lower AM, Hawthorn RJS, O'Brian F, Buchan S, Crowe AM. Adhesion-related hospital readmissions after abdominal and pelvic surgery: a retrospective cohort study. Lancet 1999;353(9163): 1476-1480.

2. Menzies D, Ellis H. Intestinal obstruction from adhesions - how big is the problem? Ann R Coll Surg Engl 1990;72(1): 60-63.

3. Parker MC, Ellis H, Moran BJ, Thompson JN, Wilson MS, Menzies D, McGuire A, Lower AM, Hawthorn RJS, O'Brian F, Buchan S, Crowe AM. Postoperative adhesions: ten-year follow-up of 12,584 patients undergoing lower abdominal surgery. Dis Colon Rectum 2001;44(6): 822-829.

4. Parker MC, Wilson MS, van Goor H, Moran BJ, Jeekel J, Duron JJ, Menzies D, Wexner SD, Ellis H. Adhesions and colorectal surgery - call for action. Colorectal Dis 2007:9 Suppl 2: 66-72.

5. Arung W, Meurisse M, Detry O. Pathophysiology and prevention of postoperative peritoneal adhesions. World J Gastroenterol 2011;17(41): 4545-4553.

6. Hirschelmann A, Tchartchian G, Wallwiener M, Hackethal A, De Wilde RL. A review of the problematic adhesion prophylaxis in gynaecological surgery. Archives of gynecology and obstetrics 2012;285(4): 1089-1097.

7. Molinas CR, Binda MM, Manavella GD, Koninckx PR. Adhesion formation after laparoscopic surgery: what do we know about the role of the peritoneal environment? Facts Views Vis Obgyn 2010;2(3): 149-160.

8. Koninckx PR, Binda MM, Corona R, Molinas CR. Postoperative adhesions and their prevention. In: Reconstructive and Reproductive Surgery in Gynecology, Gomel V, Brill AI (eds). Informa Healthcare: London, 2010; 8-17.

9. Hong G, Vilz TO, Kalff JC, Wehner S. Peritoneal adhesion formation. Der Chirurg: Zeitschrift fur alle Gebiete der operativen Medizen 2015;86(2): 175-180.

10. Suzuki S, Ikada Y. Biomaterials for Surgical Operation. Humana Press 2012.

11. diZerega GS. Contemporary adhesion prevention. Fertil Steril 1994;61(2): 219-235.

12. Ahmad G, O'Flynn H, Hindocha A, Watson A. Barrier agents for adhesion prevention after gynaecological surgery. Cochrane Database Syst Rev 2015;4: CD000475.

13. Lauder CI, Garcea G, Strickland A, Maddern GI. Use of a modified chitosan-dextran gel to prevent peritoneal adhesions in a rat model. J Surg Res 2011;171(2): 877-882.

14. Hoffmann NE, Siddiqui SA, Agarwal S, McKellar SH, Kurtz HJ, Gettman MT, Ereth MH. Choice of hemostatic agent influences adhesion formation in a rat cecal adhesion model. J Surg Res 2009;155(1): 77-81.

15. ten Broek RPG, Stommel MWJ, Strik C, van Laarhoven CJHM, Keus F, van Goor H. Benefits and harms of adhesion barriers for abdominal surgery: a systematic review and meta-analysis. The Lancet 2014;383(9911): 48-59.

16. Zeng Q, Yu Z, You J, Zhang Q. Efficacy and safety of Seprafilm for preventing postoperative abdominal adhesion: systematic review and meta-analysis. World J Surg 2007;31(11): 2125-2131; discussion 2132.

17. Poehnert D, Abbas M, Kreipe HH, Klempnauer J, Winny M. High reproducibility of adhesion formation in rat with meso-stitch approximation of injured cecum and abdominal wall. Int J Med Sci 2015;12(1): 1-6.

18. Poehnert D, Abbas M, Kreipe H-H, Klempnauer J, Winny M. Evaluation of 4 DryField ${ }^{\circledR} \mathrm{PH}$ as Adhesion Prevention Barrier Tested in an Optimized Adhesion Model (OPAM) in Rats. European Surgical Research 2015;55(4): 341-351.

19. Lalountas M, Ballas KD, Michalakis A, Psarras K, Asteriou C, Giakoustidis DE, Nikolaidou C, Venizelos I, Pavlidis TE, Sakantamis AK. Postoperative adhesion prevention using a statin-containing cellulose film in an experimental model. Br J Surg 2012;99(3): 423-429. 
20. Rajab TK, Wallwiener M, Planck CN, Brochhausen C, Krämer B, Wallwiener CW. A direct comparison of Seprafilm ${ }^{\circledR}$, Adept ${ }^{\circledR}$, Intercoat ${ }^{\circledR}$ and SprayGelTM for adhesion prophylaxis. J Surg Res 2010;161(2): 246-249.

21. Shimizu A, Suhara T, Ito T, Omichi K, Naruse K, Hasegawa K, Kokudo N. A new hepatectomy-induced postoperative adhesion model in rats, and evaluation of the efficacy of anti-adhesion materials. Surg Today 2014;44(2): 314-323.

22. Dilege E, Coskun H, Gündüz B, Sakiz D, Mihmanli M. Prevention of adhesion to prosthetic mesh in incisional ventral hernias: comparison of different barriers in an experimental model. Eur Surg Res 2006;38(3): 358-364.

23. Wallwiener $M$, Brucker S, Hierlemann $H$, Brochhausen $C$, Solomayer E, Wallwiener CW. Innovative barriers for peritoneal adhesion prevention: liquid or solid? A rat uterine horn model. Fertil Steril 2006;86(4): 1266-1276.

24. Ditzel M, Deerenberg EB, Komen N, Mulder IM, Jeekel H, Lange JF. Postoperative adhesion prevention with a new barrier: an experimental study. Eur Surg Res 2012;48(4): 187-193.

25. Müller SA, Treutner KH, Haase G, Kinzel S, Tietze L, Schumpelick V. Effect of intraperitoneal antiadhesive fluids in a rat peritonitis model. Arch Surg 2003;138(3): 286-290.

26. Irkorucu O, Ferahkose Z, Memis L, Ekinci O, Akin M. Reduction of postsurgical adhesions in a rat model: a comparative study. Clinics (Sao Paulo) 2009;64(2): 143-148.

27. Beck DE, Cohen Z, Fleshman JW, Kaufman HS, van Goor H, Wolff BG, Committee ASGS. A prospective, randomized, multicenter, controlled study of the safety of Seprafilm ${ }^{\circledR}$ adhesion barrier in abdominopelvic surgery of the intestine. Dis Colon Rectum 2003;46(10): 1310-1319.

28. Cohen Z, Senagore AJ, Dayton MT, Koruda MJ, Beck DE, Wolff BG, Fleshner PR, Thirlby RC, Ludwig KA, Larach SW, Weiss EG, Bauer JJ, Holmdahl L. Prevention of postoperative abdominal adhesions by a novel, glycerol/sodium hyaluronate/carboxymethylcellulose-based bioresorbable membrane: a prospective, randomized, evaluator-blinded multicenter study. Dis Colon Rectum 2005;48(6): 1130-1139.

29. de Lange DCD, Jeekel J. Prevalence of adhesions and the associated costs in general surgery. In: Peritoneal Surgery, diZerega GS (ed). Springer: New York, 2000; 307-320.

30. Korell M. Combined Hemostasis and Adhesion Prevention with the Novel Agent 4DryField ${ }^{\circledR}$ PH-Initial Observations. Surgical Science 2014;05(12): 533-539. 